\title{
¿Evidence for an Increasing Role of Ocean Heat in Arctic Winter Sea Ice Growth
}

\author{
Robert Ricker, ${ }^{\mathrm{a}}$ Frank Kauker, ${ }^{\mathrm{a}}$ Axel Schweiger, ${ }^{\mathrm{b}}$ Stefan Hendricks, ${ }^{\mathrm{a}}$ Jinlun Zhang, ${ }^{\mathrm{b}}$ AND \\ STEPHAN PAUL ${ }^{\mathrm{c}}$ \\ a Alfred Wegener Institute, Helmholtz Centre for Polar and Marine Research, Bremerhaven, Germany \\ ${ }^{\mathrm{b}}$ Polar Science Center, Applied Physics Laboratory, University of Washington, Seattle, Washington \\ ${ }^{\mathrm{c}}$ Department of Geography, Ludwig-Maximilians-University Munich, Munich, Germany, Germany
}

(Manuscript received 3 November 2020, in final form 9 March 2021)

\begin{abstract}
We investigate how sea ice decline in summer and warmer ocean and surface temperatures in winter affect sea ice growth in the Arctic. Sea ice volume changes are estimated from satellite observations during winter from 2002 to 2019 and are partitioned into thermodynamic growth and dynamic volume change. Both components are compared with validated sea ice-ocean models forced by reanalysis data to extend observations back to 1980 and to understand the mechanisms that cause the observed trends and variability. We find that a negative feedback driven by the increasing sea ice retreat in summer yields increasing thermodynamic ice growth during winter in the Arctic marginal seas eastward from the Laptev Sea to the Beaufort Sea. However, in the Barents and Kara Seas, this feedback seems to be overpowered by the impact of increasing oceanic heat flux and air temperatures, resulting in negative trends in thermodynamic ice growth of $-2 \mathrm{~km}^{3}$ month ${ }^{-1} \mathrm{yr}^{-1}$ on average over 2002-19 as derived from satellite observations.
\end{abstract}

KEYWORDS: Arctic; Sea ice; Remote sensing; Climate change

\section{Introduction}

The Arctic is one of the hot spots of drastic changes in Earth's climate system, a result of global warming associated with rising air temperatures (Landrum and Holland 2020). These changes are accompanied by significant declining rates in sea ice concentration and thickness during the last several decades (Comiso et al. 2008; Haas et al. 2008; Kwok and Rothrock 2009; Lindsay and Schweiger 2015; Ricker et al. 2017a; Kwok 2018).

In addition, rising ocean temperatures through the inflow of warm Atlantic Ocean water favor sea ice retreat in boreal winter (e.g., north of Svalbard) (Onarheim et al. 2014). Here we use winter as a synonym for the freezing season extending normally from November to March. The amplified oceanic heat flux into the eastern Eurasian Basin reduces the winter sea ice formation, resulting in a northward retreating ice edge as well as thinner sea ice in the Eurasian Basin (Polyakov et al. 2017, 2020). This so-called "Atlantification" substantially controls the sea ice cover in the Barents Sea (Onarheim and Årthun 2017). At the same time, we have observed the four lowest maximum Arctic sea ice extents within the last five years, and 2020 just marked the second lowest minimum on record (Meier et al. 2020).

Model studies in turn show a negative feedback mechanism in winters following summers with strong melting: that is, a stabilizing feedback, which allows the sea ice to recover from summers with low sea ice extents (Bitz and Roe 2004; Stroeve and Notz 2015; Stroeve et al. 2018). The general decline of sea ice extent and thickness in summer seems to foster a positive trend in thermodynamic ice growth in winter over the last decades. Analyzing sea ice thickness

¿ Denotes content that is immediately available upon publication as open access.

Corresponding author: Robert Ricker, robert.ricker@awi.de from CryoSat-2 satellite data and model simulations, Petty et al. (2018) find that the negative feedback occurs in the eastern Arctic and is likely to be intensified in the western Arctic in coming years. But the study also stresses that this increasing winter ice growth will not stop the general loss of Arctic sea ice. While Petty et al. (2018) distinguish between thermodynamic and dynamic ice growth from models, ice growth from satellite observations is assessed with regard to changes in thickness only.

To quantitatively investigate the winter sea ice growth, it is crucial to separate the thermodynamic ice growth from dynamic changes of sea ice volume through advection, which has not been fully explored yet using observational data. While the thermodynamic growth in the Arctic is mainly controlled by surface air and ocean temperatures, wind and ocean currents are the drivers for dynamic ice volume changes. Eventually, spatial sea ice volume anomalies are a result of the interaction between the dynamics and thermodynamics.

We test the hypothesis that the stabilizing feedback of winter ice growth is reduced by the rising impact of warmer ocean and surface temperatures in the European sector of the marginal seas, including the Barents and Kara Seas (Fig. 1). Therefore, we aim to quantify changes and trends in winter sea ice growth based on observations. We use satellite-derived data records of sea ice thickness, concentration, and drift from 2002 to 2019 to estimate winter sea ice volume changes and fluxes to discriminate between dynamic volume changes and thermodynamic ice growth. In addition, we use atmospheric reanalysis driven sea ice-ocean model simulations and reanalysis data of winds and air temperature covering the period 1980-2019 to better understand the mechanisms behind our findings and to extend the analysis based on satellite observations backward in time.

\section{Methods and data}

\section{a. Selected regions}

We have selected six Arctic regions that coarsely follow the boundaries of the marginal Arctic seas along the circumpolar 


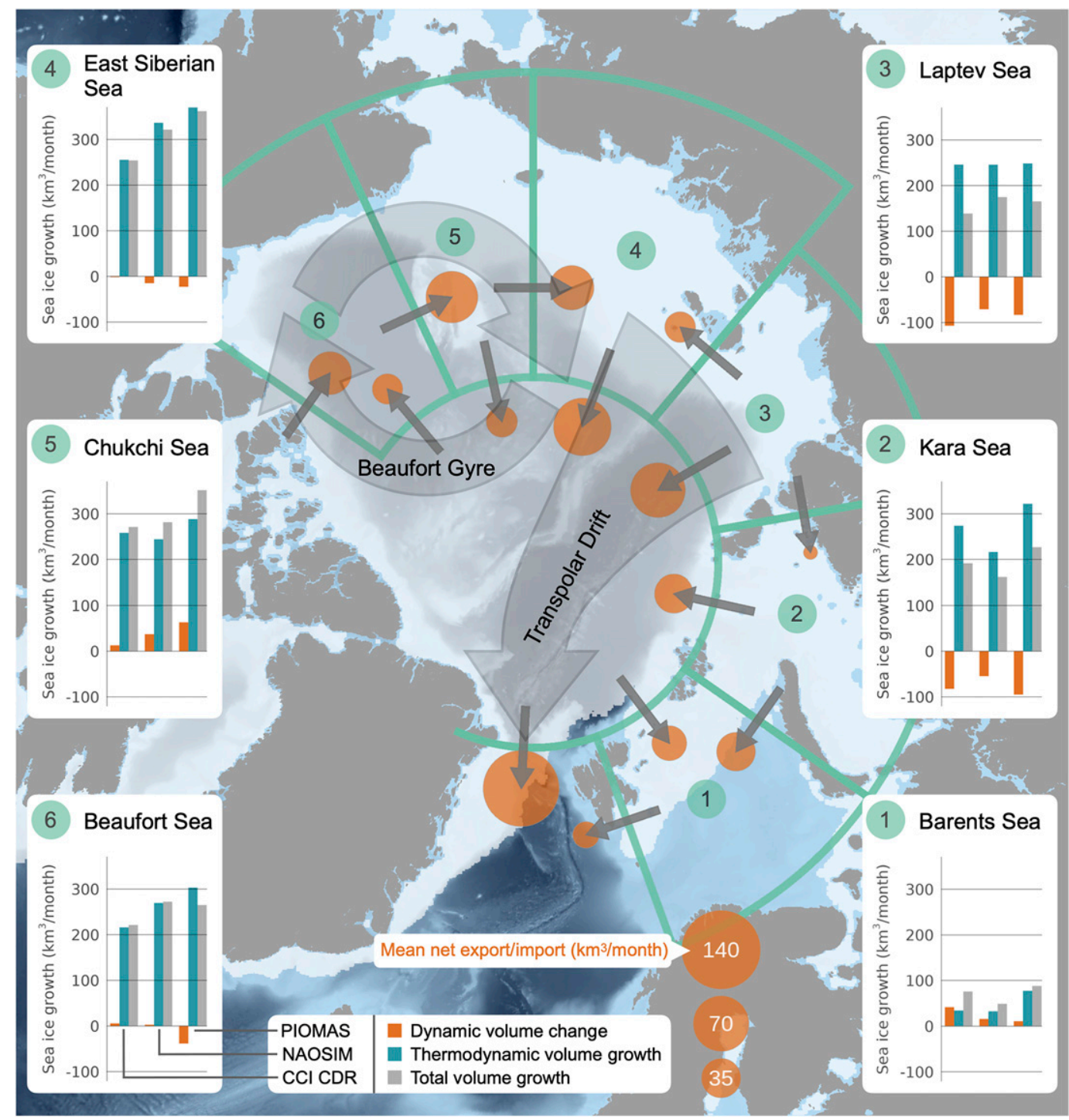

FIG. 1. Overview map illustrating selected study regions and corresponding net winter (NovemberMarch) sea ice export/import through meridional and zonal boundaries from 2002 to 2019 using satellitederived sea ice volume fluxes (orange slices). Bar charts illustrate mean winter dynamic ice volume growth, mean winter thermodynamic growth, and mean winter total volume growth from 2002 to 2019 for models NAOSIM and PIOMAS and for satellite-derived CCI CDR. Negative values indicate net export or melt of sea ice.

coasts (Fig. 1). The northern boundaries are at $81.0^{\circ} \mathrm{N}$, while the southern boundaries are mainly given by the coastline. We think that the interplay between competing processes and mechanisms is highlighted in these regions. Moreover, continuous satellite-derived ice thickness information is limited to $<81.4^{\circ} \mathrm{N}$.

\section{b. Sea ice growth derived from satellites}

To evaluate sea ice growth during the freezing season, we have developed an approach to separate dynamic volume changes and thermodynamic sea ice growth using satellite observations. To achieve this, we first estimate sea ice volume flux, which requires the multiplication of sea ice motion, thickness, and concentration (Ricker et al. 2018).

In this study, we use the Centre ERS d'Archivage et de Traitement (CERSAT) sea ice motion dataset, which is derived from merging satellite measurements from passive microwave and scatterometry data (Girard-Ardhuin and Ezraty 2012). CERSAT provides a consistent and validated time series of monthly motion vector grids with a spatial resolution of $62.5 \mathrm{~km}$ for the entire Arctic, starting from 1991, showing an appropriate performance in the circumpolar regions (Krumpen et al. 2019; Sumata et al. 2014). 
The climate data record from the ESA Climate Change Initiative (CCI) provides monthly gridded Arctic sea ice thickness with a spatial resolution of $25 \mathrm{~km}$. The data record covers the period from 2002-19 and is based on Envisat (2002-12) and CryoSat-2 (2010-19) radar altimetry (Hendricks et al. 2018a,b). Within the CCI, satellite range measurements have been processed into sea ice freeboard and thickness eventually, ensuring consistency between both satellite missions (Paul et al. 2018). The retrieval method only allows for data retrievals over the freezing season from October to April due to melt ponds in the summer months that interfere with the separation of range measurements from the ice surface and the sea surface (Ricker et al. 2014; Tilling et al. 2018). Uncertainties are caused by the different sensor characteristics, which result in different sensitivities to sea ice surface properties (Belter et al. 2020; Khvorostovsky et al. 2020). Another important contribution to the error budget is the impact of snow. On the one hand, the interannual variability of snow depth (Webster et al. 2018) is not represented in the climatology, which is applied to retrieve sea ice thickness from radar altimetry (Ricker et al. 2017b). On the other hand, previous studies suggest that the snow properties can alter the altimetric measurements of the satellite (Ricker et al. 2015; King et al. 2018; Nandan et al. 2017).

For sea ice concentration, we use the climate data record generated by the EUMETSAT Ocean and Sea Ice Satellite Application Facility (OSI SAF), in collaboration with ESA CCI. This record includes the interim climate data record (2016-19; OSI-430-b) that is an extension of the OSI SAF CDR (1980-2015; OSI-450; Lavergne et al. 2019). Sea ice concentration is obtained from passive microwave satellite data over the polar region and is provided daily on a grid with a resolution of $25 \mathrm{~km}$.

Sea ice motion, thickness, and concentration are reprojected and interpolated on monthly 25-km Equal-Area Scalable Earth (EASE-2) grids (Brodzik et al. 2012). Following Ricker et al. (2018), we calculate monthly sea ice volume fluxes in the Arctic, and specifically at the two meridional and two zonal boundaries for each of the six regions. Due to the geography, fluxes through the southern boundaries are nearly neglectable, with minor contributions in the Barents Sea and Chukchi Sea (through the Bering Strait). Then, we estimate the monthly dynamic sea ice volume change $\Delta V_{\text {dyn }}$ of a region as the net sum of the fluxes through the boundaries of each region. Negative values correspond to ice export, while positive values represent import of sea ice.

In a second step, monthly sea ice volume is calculated from sea ice thickness and concentration for each region (Ricker et al. 2017a). Monthly sea ice volume growth $\Delta V$ is estimated by a three-point Lagrangian interpolation. Therefore, we obtain satellite-derived $\Delta V$ for November-March from 2002 to 2019, covering 17 winter seasons.

We obtain the thermodynamic sea ice volume growth $\Delta V_{\text {thd }}=\Delta V-\Delta V_{\text {dyn }}$. Negative values correspond to ice melt, while positive values represent growth of sea ice. In this study, we refer to the satellite-derived sea ice volume growth as CCI CDR (Climate Change Initiative Climate Data Record).
Because of the limitations in spatial and temporal resolution of satellite measurements, only monthly estimates of sea ice volume flux and thickness with $25-\mathrm{km}$ grid resolution are feasible. The terms $\Delta V_{\text {dyn }}$ and $\Delta V_{\text {thd }}$ are estimated for larger regions in order to reduce the level of uncertainty.

\section{c. Sea ice growth from model simulations}

The sea ice-ocean model NAOSIM (North Atlantic/ Arctic Ocean-Sea Ice Model; Gerdes et al. 2003; Kauker et al. 2003) has demonstrated its merits in numerous studies on the Arctic's ocean circulation and hydrography, on sea ice variability, and in tracer studies. The sea ice part of the model uses the viscous plastic (VP) rheology (Hibler 1979). The thermodynamics of sea ice and snow is given by the so-called zero-layer formulation (Semtner 1976) and the implementation is based on Owens and Lemke (1990) with some modifications [e.g., implementation of ridging like in Flato and Hibler (1991), and a subgrid-scale parameterization of ice thickness following CastroMorales et al. (2014)]. The ocean part of the model is based on the Modular Ocean Model, version 2 (MOM-2), developed at the Geophysical Fluid Dynamics Laboratory (Pacanowski 1995), and is coupled to the sea ice following the formulation of Hibler and Bryan (1987). The model is formulated on a spherical rotated grid covering the whole Arctic and the North Atlantic Ocean north of approximately $50^{\circ} \mathrm{N}$. The geographical North Pole is shifted to $60^{\circ} \mathrm{E}$ on the equator to realize nearly equidistant grid cells over the model domain. For the current study we employ a mediumresolution version of NAOSIM with $28 \times 28 \mathrm{~km}^{2}$ horizontal resolution and 30 levels. Open boundary condition has been implemented along the model boundaries following Stevens (1991). Temperature and salinity at inflow points of the Atlantic sector are restored toward the Polar Science Center Hydrographic Climatology (PHC; Steele et al. 2001).

The initial condition (year 1980) for the simulation employed here is given by a 32-yr integration (1948-80) with the National Centers for Environmental Prediction (NCEP)National Center for Atmospheric Research (NCAR) reanalysis forcing (Kalnay et al. 1996) starting from temperature and salinity fields given by the PHC climatology and $100 \%$ sea ice concentration with 2-m thickness in regions where the sea surface temperature falls below the freezing point temperature of seawater. The model is driven by 6-hourly forcing of 2-m air temperature, 2-m specific humidity, surface downward long- and shortwave radiation, 10-m surface wind, and total precipitation from the NCEP Climate Forecast System Reanalysis (Saha et al. 2010) for 1980-2010 and from the NCEP Climate Forecast System, version 2 (Saha et al. 2014), for 2011-19.

Recently the models' parameters have been optimized with the help of a micro genetic algorithm, which strongly improved the performance with respect to sea ice concentration, thickness, and drift (Sumata et al. 2019a,b). Although a variational assimilation system based on an adjoint code for NAOSIM exists, no data are assimilated in the simulation used here in order to allow for a homogenous quality over the period 1980-2019. The model variables analyzed in this study are the state variables sea ice thickness and concentration and the dynamic and thermodynamic sea ice growth as well as the heat flux 

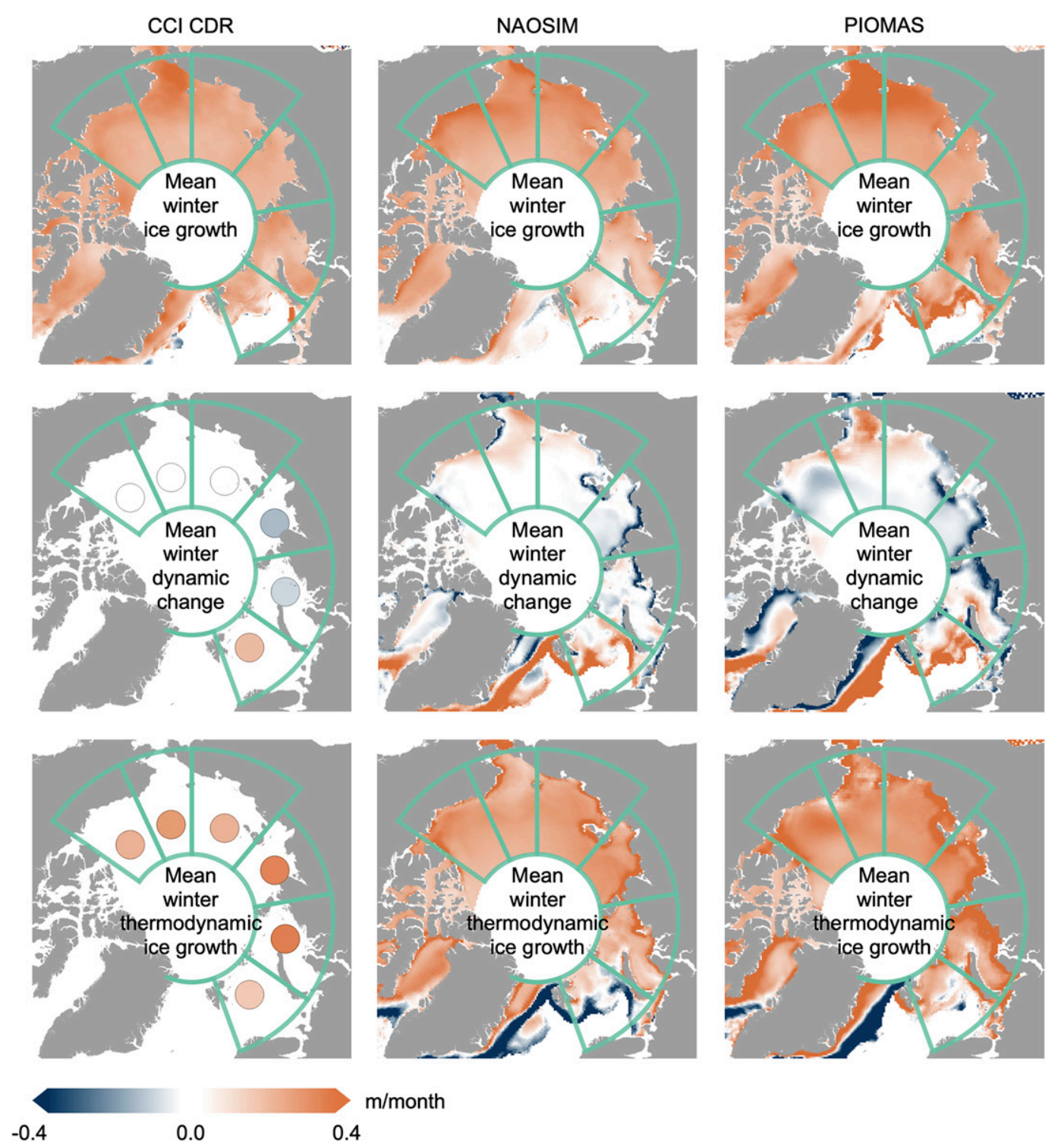

$\mathrm{m} / \mathrm{month}$

FIG. 2. (top) Mean sea ice growth, (middle) mean dynamic volume change, and (bottom) mean thermodynamic sea ice growth over winter (November-March) seasons from 2002 to 2019 by (left) CCI CDR, (right) PIOMAS, and (center) NAOSIM. The green grid corresponds to the selected regions given in Fig. 1.

from the ocean into the sea ice (bottom melt). All variables are bookkept in the model during the simulation for each time step $(5400 \mathrm{~s})$ and monthly means are stored for the present analysis.

The Pan-Arctic Ice-Ocean Modeling and Assimilation System (PIOMAS) consists of the thickness and enthalpy distribution sea ice model (Schweiger et al. 2011; Zhang and Rothrock 2003) coupled with the POP (Parallel Ocean Program) ocean model (Smith et al. 1992). Atmospheric forcing data are identical to NAOSIM except that precipitation and evaporation are also derived from corresponding NCEP-NCAR reanalysis fields. Reanalysis forcing is used to drive PIOMAS simulations, with daily satellite sea ice concentration and sea surface temperature assimilated. PIOMAS has been validated extensively against observations of sea ice thickness, volume (Schweiger et al. 2011; Laxon et al. 2013; Stroeve et al. 2014; Wang et al. 2016; Labe et al. 2018), and ice motion (Zhang et al. 2012). It is widely used for comparison with global climate simulates (e.g., Keen et al. 2021). Monthly mean sea ice thickness, ice concentration, convergence of ice thickness, and net ice production due to surface heating/cooling and ocean heat flux are used to calculate sea ice volume growth due to dynamics and thermodynamics. Lateral boundary conditions are provided by a similarly configured global model also forced with NCEPNCAR reanalysis. 
a Mean winter dynamic volume change (Nov-Mar)
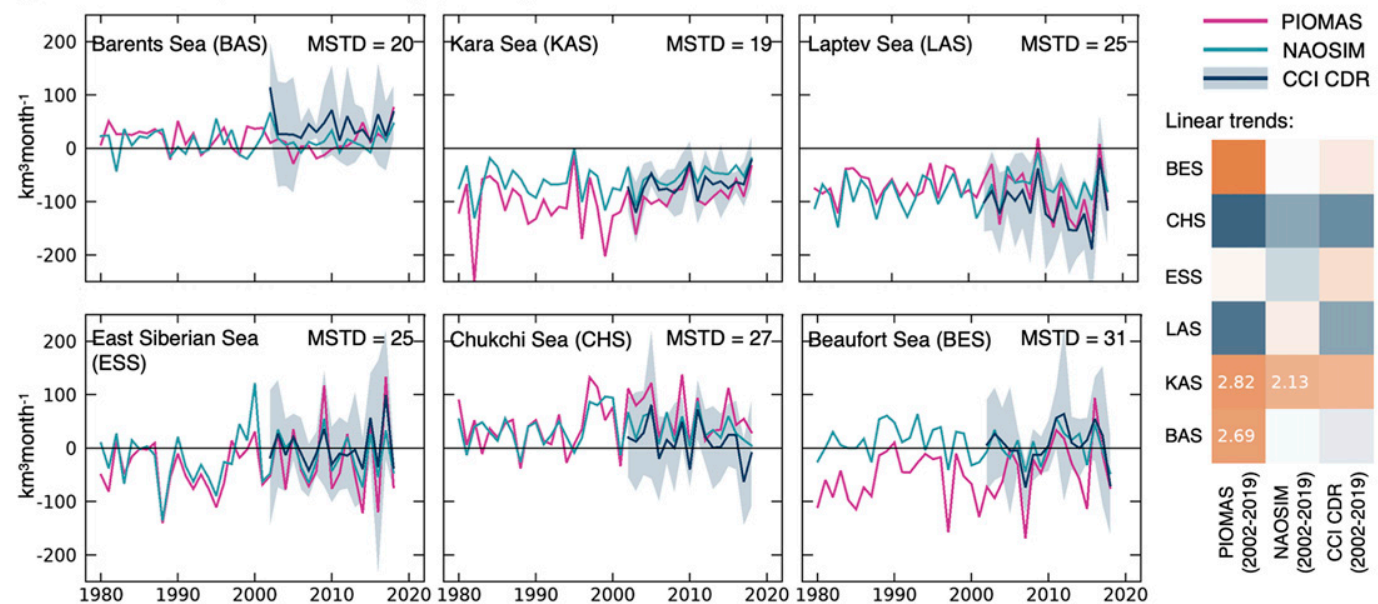

b Mean winter thermodynamic volume growth (Nov-Mar)
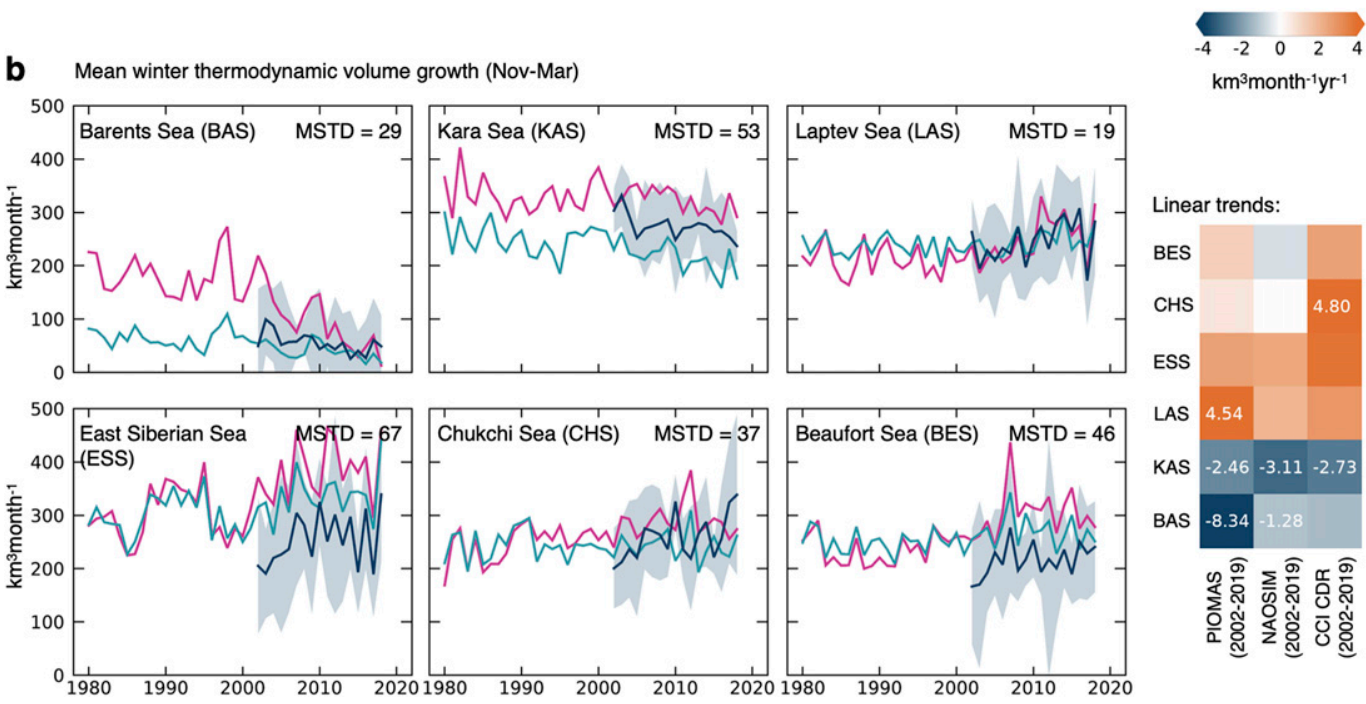

FIG. 3. (a) Mean winter dynamic sea ice volume change (November-March) and (b) mean winter thermodynamic sea ice volume growth for circumpolar regions, given by PIOMAS, NAOSIM, and the CCI CDR dataset. Blue shading represents the standard deviation of the satellite-derived CCI CDR retrievals for each winter season. MSTD is the mean standard deviation of monthly volume growth rates from the different data records $\left(\mathrm{km}^{3}\right.$ month $\left.{ }^{-1}\right)$. Linear trends for 2002-19 are given on the right of the figure; numbers, if shown, indicate that the given linear regression coefficient (trend) is significant.

\section{d. Sea ice age}

This data record is retrieved from NSIDC (National Snow and Ice Data Center) and provides weekly estimates of sea ice age for the Arctic Ocean derived from satellite products of sea ice motion and sea ice extent (Tschudi et al. 2019). We here use the version-4 dataset, which covers the period from 1984 to 2019. Sea ice is classified into 16 age classes, from which we pool together sea ice age $>5$ years.

\section{e. Reanalysis data records}

Reanalysis data of atmospheric parameters are provided by the National Oceanic and Atmospheric Administration (NOAA). Here we use the NCEP-DOE Reanalysis 2 that provides air temperature at $2 \mathrm{~m}$ above surface and northward/eastward wind velocity components on Gaussian grids at $10 \mathrm{~m}$ above surface from 1980 to 2019 (Kanamitsu et al. 2002).

\section{Results and discussion}

\section{a. Spatial patterns of sea ice growth}

Figure 2 shows the spatial patterns of mean winter (NovemberMarch) ice growth from CCI CDR, NAOSIM, and PIOMAS, averaged over the period 2002-19. The different behavior of the models in the Chukchi Sea can be attributed to open boundary effects of NAOSIM, which is a regional pan-Arctic model with a boundary in the Bering Strait. Figure 2 also presents both ice growth components. For CCI CDR, due to 
TABLE 1. Intercomparison between winter thermodynamic ice growth $\Delta V_{\text {dyn }}$ and dynamic volume change $\Delta V_{\text {thd }}$ retrievals from CCI CDR, NAOSIM, and PIOMAS, with respect to Pearson correlation coefficient $r$, root-mean-square deviation (RMSD), and mean bias (bias).

\begin{tabular}{|c|c|c|c|c|c|c|}
\hline & \multicolumn{3}{|c|}{$\Delta V_{\text {thd }}$} & \multicolumn{3}{|c|}{$\Delta V_{\mathrm{dyn}}$} \\
\hline & $r$ & $\operatorname{RMSD}\left(\mathrm{km}^{3}\right)$ & $\operatorname{Bias}\left(\mathrm{km}^{3}\right)$ & $r$ & $\operatorname{RMSD}\left(\mathrm{km}^{3}\right)$ & $\operatorname{Bias}\left(\mathrm{km}^{3}\right)$ \\
\hline PIOMAS-NAOSIM & 0.77 & 61 & 46 & 0.75 & 60 & -12 \\
\hline NAOSIM-CCI CDR & 0.35 & 83 & 12 & 0.81 & 41 & 6 \\
\hline PIOMAS-CCI CDR & 0.38 & 103 & 58 & 0.71 & 65 & -7 \\
\hline
\end{tabular}

the retrieval method, we only obtain individual values for dynamic and thermodynamic ice growth for each region, while the models provide spatial patterns.

To estimate volume changes in the selected regions, the modeled dynamic and thermodynamic monthly ice growth fields are multiplied with the ice-covered area, also given by the models. Monthly $\Delta V_{\text {dyn }}$ and $\Delta V_{\text {thd }}$ for each region are then derived by summing up the gridcell volumes of the dynamic and thermodynamic contributions. We finally retrieve time series of monthly $\Delta V, \Delta V_{\mathrm{dyn}}$, and $\Delta V_{\text {thd }}$ from satellite observations (CCI CDR) and the two models (NAOSIM, PIOMAS).

\section{b. Winter sea ice growth in selected Arctic regions}

In this study, we define thermodynamic sea ice growth $\Delta V_{\text {thd }}$ as a result of freezing or melting, and dynamic volume changes $\Delta V_{\text {dyn }}$ as a result of sea ice advection. We find that the total volume growth $\Delta V$ is dominated by $\Delta V_{\text {thd }}$ in the Beaufort Sea (BES), Chukchi Sea (CHS), and East Siberian Sea (ESS) as illustrated in Fig. 1. Sea ice in the BES and CHS is mainly advected by the Beaufort Gyre, causing significant exchange of sea ice through the meridional and zonal sections defining the boundaries of the selected regions (Fig. 1). But sea ice export out of the BES, CHS, or ESS is mostly balanced by sea ice import from other regions, resulting in a mean $\Delta V_{\mathrm{dyn}}$ in winters of $2002-19$ of less than $5 \%$ of the total $\Delta V$.

The Barents Sea (BAS), Kara Sea (KAS), and Laptev Sea (LAS) show different characteristics. LAS and KAS are regions with negative $\Delta V_{\text {dyn }}$, meaning that sea ice volume is decimated by sea ice export, mainly through the Northern boundaries. For LAS and KAS, the mean $\Delta V_{\text {dyn }}$ over winter is -107 and $-68 \mathrm{~km}^{3}$ month $^{-1}$, respectively. The mean winter $\Delta V$ of BAS is relatively small in comparison with the other regions, with a relative contribution of $55 \%$ by $\Delta V_{\text {dyn }}$ and $45 \%$ by $\Delta V_{\text {thd }}$.

Sea ice-ocean model simulations with NAOSIM and PIOMAS are analyzed for the period 1980-2019. The models reveal similar relations between $\Delta V_{\text {dyn }}$ and $\Delta V_{\text {thd }}$ for the various regions but differ in magnitudes (Fig. 1).

Figure 3 shows $\Delta V_{\text {dyn }}$ and $\Delta V_{\text {thd }}$ time series averaged over the winter seasons for the selected regions. The range of magnitudes of mean winter $\Delta V_{\text {dyn }}$ and $\Delta V_{\text {thd }}$ of the three different products is measured by the ensemble mean standard deviation (MSTD). We find the largest MSTD in ESS for

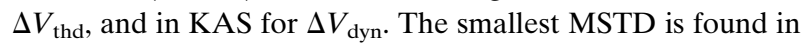
LAS for $\Delta V_{\text {thd }}$ and in BAS for $\Delta V_{\text {dyn }}$.
Table 1 provides a summary of root-mean-square deviation (RMSD), mean bias and correlation coefficients between the three sources of $\Delta V_{\mathrm{dyn}}$ and $\Delta V_{\text {thd }}$ for 2002-19. We find better agreement between models and the satellite-derived product for $\Delta V_{\text {dyn }}$ than for $\Delta V_{\text {thd. }}$ This is likely due to the lower variability of $\Delta V_{\text {thd }}$ and because the satellite-derived $\Delta V_{\text {thd }}$ is obtained indirectly from $\Delta V-\Delta V_{\text {dyn }}$, adding additional uncertainties. NAOSIM and PIOMAS use similar underlying
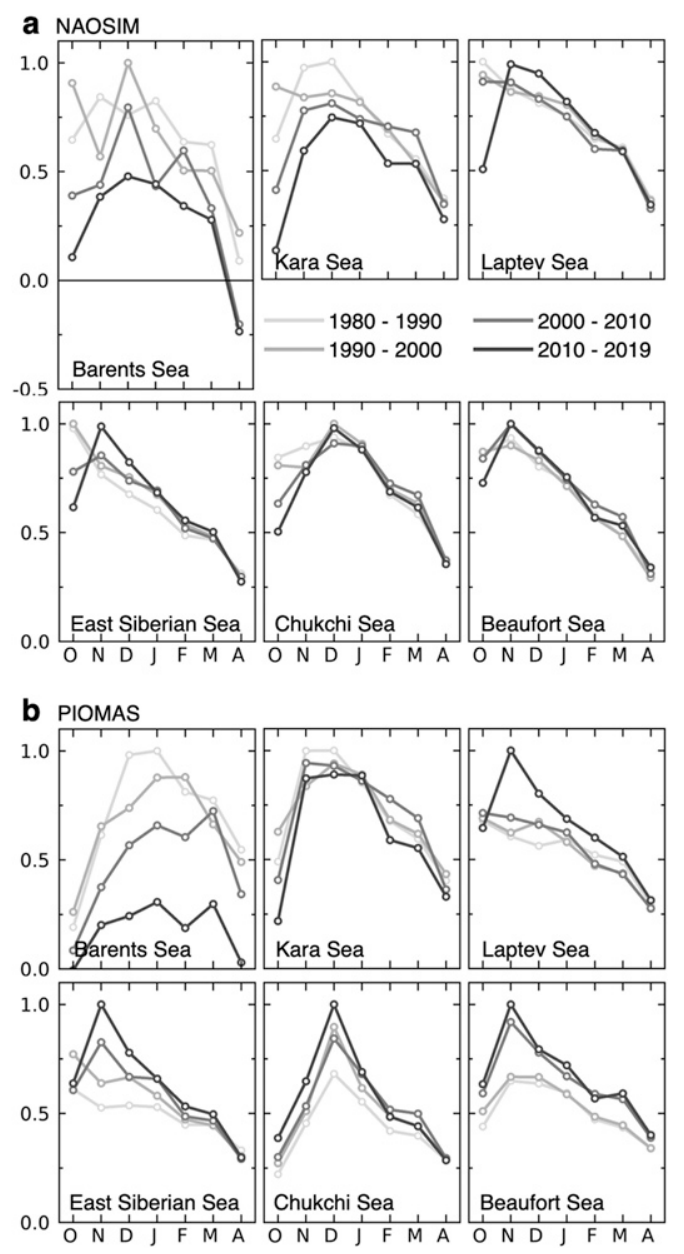

FIG. 4. Normalized mean monthly thermodynamic volume growth through the winter season, grouped into four decades, derived from (a) NAOSIM and (b) PIOMAS. 
TABLE 2. Linear trends of mean winter dynamic sea ice volume change $\left(\mathrm{km}^{3} \mathrm{month}^{-1} \mathrm{yr}^{-1}\right)$ with corresponding standard error. Trends are given for marginal seas, the European marginal seas (EMS), and the North America-Asia marginal seas (NAMS). For EMS and NAMS we consider ensemble means over PIOMAS, NAOSIM, and CCI CDR. Boldface values indicate significance using a significance level of $5 \%$.

\begin{tabular}{|c|c|c|c|c|c|}
\hline & \multicolumn{2}{|c|}{ 1980-2002 } & \multicolumn{3}{|c|}{$2002-19$} \\
\hline & PIOMAS & NAOSIM & PIOMAS & NAOSIM & CCI CDR \\
\hline Barents Sea & $-0.35 \pm 0.70$ & $-0.31 \pm 0.80$ & $2.69 \pm 1.03$ & $-0.11 \pm 1.04$ & $-0.44 \pm 1.33$ \\
\hline Kara Sea & $-0.87 \pm 1.82$ & $-0.43 \pm 1.05$ & $2.82 \pm 1.32$ & $\mathbf{2 . 1 3} \pm \mathbf{0 . 8 9}$ & $2.01 \pm 1.09$ \\
\hline Laptev Sea & $0.22 \pm 0.86$ & $0.52 \pm 1.05$ & $-2.84 \pm 2.69$ & $0.45 \pm 1.55$ & $-1.89 \pm 2.10$ \\
\hline East Siberian Sea & $0.20 \pm 1.53$ & $0.81 \pm 1.82$ & $0.21 \pm 3.87$ & $-0.80 \pm 2.02$ & $0.84 \pm 1.95$ \\
\hline Chukchi Sea & $0.87 \pm 1.52$ & $1.44 \pm 1.16$ & $-3.16 \pm 2.01$ & $-1.82 \pm 1.33$ & $-2.36 \pm 1.74$ \\
\hline \multirow[t]{2}{*}{ Beaufort Sea } & $0.95 \pm 1.55$ & $-0.14 \pm 1.07$ & $3.48 \pm 2.96$ & $-0.05 \pm 1.59$ & $0.53 \pm 1.90$ \\
\hline & \multicolumn{2}{|c|}{ Ensemble mean } & \multicolumn{3}{|c|}{ Ensemble mean } \\
\hline EMS & \multicolumn{2}{|c|}{$-0.98 \pm 1.75$} & \multicolumn{3}{|c|}{$3.03 \pm 1.72$} \\
\hline NAMS & \multicolumn{2}{|c|}{$2.44 \pm 3.07$} & \multicolumn{3}{|c|}{$-2.47 \pm 4.98$} \\
\hline
\end{tabular}

physics explaining the better agreement among the modeled estimates of $\Delta V_{\text {thd }}$.

\section{c. Trends in winter sea ice growth}

Annual trends of mean monthly $\Delta V_{\mathrm{dyn}}$ and $\Delta V_{\text {thd }}$ during winter are estimated using a linear regression model and are assessed with regard to their significance at the $95 \%$ confidence level. Over the period 2002-19, we only find significant positive trends for $\Delta V_{\text {dyn }}$ in the KAS (PIOMAS, NAOSIM) and in the BAS (PIOMAS). LAS, ESS, CHS, and BES reveal substantial interannual variability and no significant trends of $\Delta V_{\text {dyn }}$ (Fig. 3a). There is no clear evidence for a long-term change in $\Delta V_{\text {dyn. }}$.

We find positive trends of $\Delta V_{\text {thd }}$ in the LAS, ESS, CHS, and BES, but only significant in the CHS for CCI CDR $\left(4.8 \mathrm{~km}^{3}\right.$ month $\left.{ }^{-1} \mathrm{yr}^{-1}\right)$ and in LAS for PIOMAS $\left(4.54 \mathrm{~km}^{3}\right.$ month $\left.{ }^{-1} \mathrm{yr}^{-1}\right)$. While individually not statistically significant, the fact that these adjacent regions collectively have all slightly positive trends is evidence for the continued negative winter ice growth feedback in response to summer melt.

In contrast, $\Delta V_{\text {thd }}$ reveals significant negative trends for BAS and KAS among almost all $\Delta V_{\text {thd }}$ estimates (Fig. 3b). The $\Delta V_{\text {thd }}$ trends derived from CCI CDR in the BAS $\left(-1.39 \mathrm{~km}^{3}\right.$ month $\left.{ }^{-1} \mathrm{yr}^{-1}\right)$ and KAS $\left(-2.73 \mathrm{~km}^{3}\right.$ month $\left.^{-1} \mathrm{yr}^{-1}\right)$ are in between trends found for NAOSIM and PIOMAS. Except for $\mathrm{CHS}$ and $\mathrm{BES}$, trends in $\Delta V_{\text {thd }}$ are consistent with regard to their tendencies among all the three products, but with different magnitudes. The broad agreement of observational and modeled ice change components provides confidence that model simulations can be used to further probe the underlying mechanism for the observed changes.

We use the model simulations to extend the time series of winter ice growth into the past starting in 1980. Figure 4 shows the mean monthly $\Delta V_{\text {thd }}$ of NAOSIM and PIOMAS in the winter seasons from 1980-2019, grouped into four time periods of a length of one decade. As a consequence of delayed or slowed freeze up, LAS, ESS, CHS, and BES show a decrease for October in the NAOSIM simulations, followed by a steep increase for November, where winter ice growth in the last decade most of the times exceeds growth in previous decades. For PIOMAS, this is only the case in the LAS and ESS. Both model simulations reveal an increasing monthly $\Delta V_{\text {thd }}$ over the November-March period from 1980 to 2019 for LAS, ESS, CHS, and BES. In contrast, NAOSIM and PIOMAS indicate a decrease in $\Delta V_{\text {thd }}$ for almost all months in the BAS and KAS.

There is evidence that these regional trends have strengthened within the last two decades. Tables 2 and 3 add trends from 1980 to 2002 to trends given in Fig. 3 from 2002 to 2019. We find stronger trends for the 2002-19 period and especially for the decrease of $\Delta V_{\text {thd }}$ in the BAS and KAS. In fact, the only

TABLE 3. As in Table 2, but for mean winter thermodynamic sea ice volume growth $\left(\mathrm{km}^{3} \mathrm{month}^{-1} \mathrm{yr}^{-1}\right)$.

\begin{tabular}{|c|c|c|c|c|c|}
\hline & \multicolumn{2}{|c|}{ 1980-2002 } & \multicolumn{3}{|c|}{ 2002-19 } \\
\hline & PIOMAS & NAOSIM & PIOMAS & NAOSIM & CCI CDR \\
\hline Barents Sea & $-1.07 \pm 1.10$ & $-0.32 \pm 0.42$ & $-8.34 \pm 1.48$ & $-1.28 \pm 0.47$ & $-1.39 \pm 0.86$ \\
\hline Kara Sea & $-0.29 \pm 1.10$ & $-0.65 \pm 0.94$ & $-2.46 \pm 0.98$ & $-3.11 \pm 1.09$ & $-2.73 \pm 0.95$ \\
\hline Laptev Sea & $-0.50 \pm 0.98$ & $-0.37 \pm 0.64$ & $4.54 \pm 1.91$ & $2.01 \pm 1.14$ & $2.88 \pm 1.84$ \\
\hline East Siberian Sea & $0.64 \pm 1.66$ & $0.08 \pm 1.32$ & $2.60 \pm 2.67$ & $2.43 \pm 2.10$ & $3.88 \pm 2.38$ \\
\hline Chukchi Sea & $2.61 \pm 0.99$ & $-0.04 \pm 0.95$ & $0.67 \pm 1.70$ & $0.02 \pm 1.37$ & $4.80 \pm 1.74$ \\
\hline \multirow[t]{2}{*}{ Beaufort Sea } & $0.78 \pm 0.97$ & $-0.34 \pm 0.75$ & $1.31 \pm 2.30$ & $-0.67 \pm 1.48$ & $2.59 \pm 1.41$ \\
\hline & \multicolumn{2}{|c|}{ Ensemble mean } & \multicolumn{3}{|c|}{ Ensemble mean } \\
\hline EMS & \multicolumn{2}{|c|}{$-1.16 \pm 1.17$} & \multicolumn{3}{|c|}{$-6.43 \pm 1.23$} \\
\hline NAMS & \multicolumn{2}{|c|}{$1.43 \pm 2.74$} & \multicolumn{3}{|c|}{$9.02 \pm 4.14$} \\
\hline
\end{tabular}



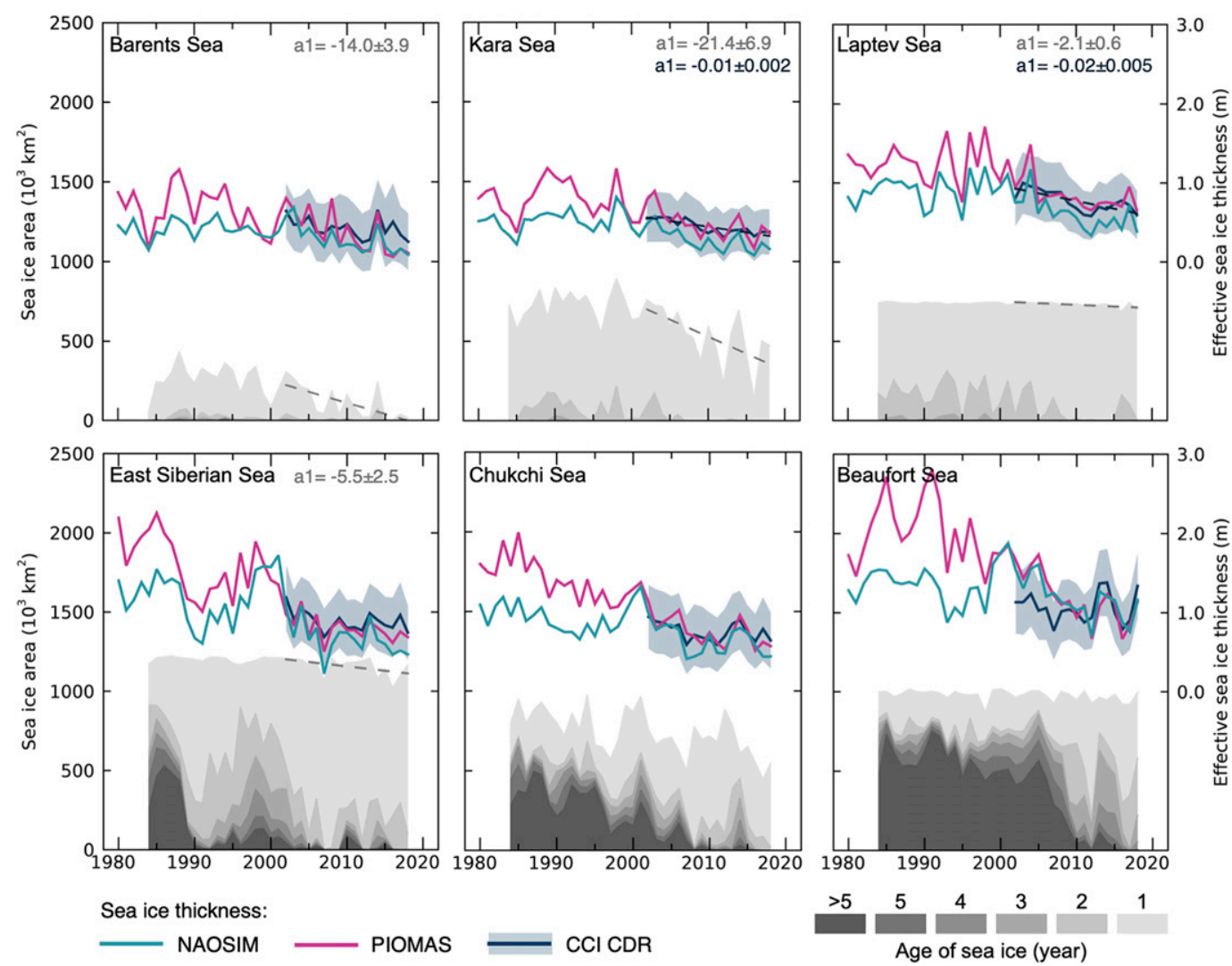

FIG. 5. Effective sea ice thickness (grid cell ice volume divided by grid cell area), ice area, and age for circumpolar regions in November. Gray-shaded areas provide total area and its partitioning by age. Blue shading represents uncertainties of the CCI CDR retrieval. Linear regression coefficients a1 (2002-19) of CCI CDR ice thickness (black) and sea ice area (gray) are given where trends are significant at the $95 \%$ confidence level. The regressions are highlighted as dashed lines.

significant trend for the 1980-2002 period is given for $\Delta V_{\text {thd }}$ (PIOMAS) in the CHS $\left(2.61 \mathrm{~km}^{3}\right.$ month $\left.^{-1} \mathrm{yr}^{-1}\right)$.

This observational evidence, corroborated by modeling studies, suggests that the winter Arctic can be separated into two regions: The North America-Asia marginal seas (NAMS) including LAS, ESS, CHS, and BES and the European marginal seas (EMS) including BAS and KAS. In fact, considering the ensemble means over PIOMAS, NAOSIM, and CCI CDR, we find a significant negative trend in $\Delta V_{\text {thd }}$ for the EMS $\left(-6.43 \mathrm{~km}^{3}\right.$ month $\left.^{-1} \mathrm{yr}^{-1}\right)$ and a significant positive trend for the NAMS $\left(9.02 \mathrm{~km}^{3}\right.$ month $\left.^{-1} \mathrm{yr}^{-1}\right)$ in the $2002-19$ period (Table 3).

The increase in winter $\Delta V_{\text {thd }}$ in the NAMS can be expected in response to increased summer melt, consistent with the negative ice growth feedback stabilization mechanism. However, there is no evidence of an active ice growth feedback in the EMS, suggesting that a different mechanism dominates. What are these different processes and mechanisms?

\section{d. Processes and mechanisms that drive changes in winter ice growth}

We use information of satellite-derived ice conditions, simulated melt through ocean heat flux, and reanalysis air temperature and wind data, to understand observed changes and variability in $\Delta V_{\text {dyn }}$ and $\Delta V_{\text {thd }}$.

Sea ice conditions at the beginning of the winter are important for the following ice growth period (Stroeve et al. 2018; Petty et al. 2018). Figure 5 shows the ice age and corresponding area, together with effective sea ice thickness in November from satellite observations and models. BAS, KAS, and LAS are characterized by first-year ice (FYI), and occasionally second-year ice. ESS and CHS reveal a decrease in multiyear sea ice (MYI), with a fraction of $<50 \%$ in recent years, while MYI in the BES still dominates, although older ice ( $>2 \mathrm{yr}$ ) has shrunk significantly over the last decades. The retreat of older sea ice goes along with a decrease in sea ice thickness, indicated by models and satellite observations. We find significant trends in CCI CDR sea ice thickness in November in the KAS $\left(-0.01 \mathrm{~m} \mathrm{yr}^{-1}\right)$ and LAS $\left(-0.02 \mathrm{~m} \mathrm{yr}^{-1}\right)$ over 2002-19. Also, the ice area is shrinking showing significant negative trends in the BAS, KAS, LAS, and ESS. The observed reduced ice area and thickness in November favors the negative ice growth feedback.

In addition to the initial conditions in November, we investigate winter surface air temperatures, ocean heat fluxes from NAOSIM and PIOMAS, and wind velocities (Fig. 6). We 


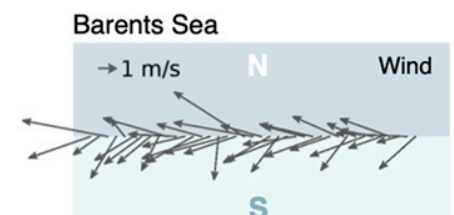

S

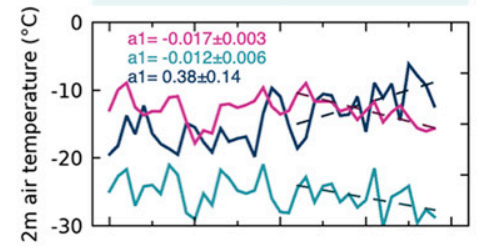

East Siberian Sea

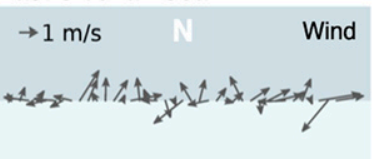

S

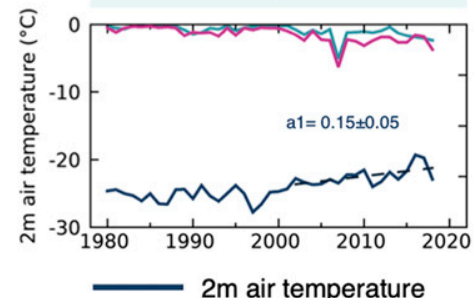

Kara Sea

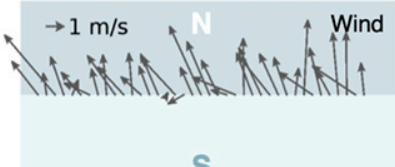

S

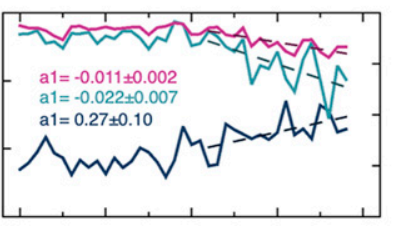

Chukchi Sea
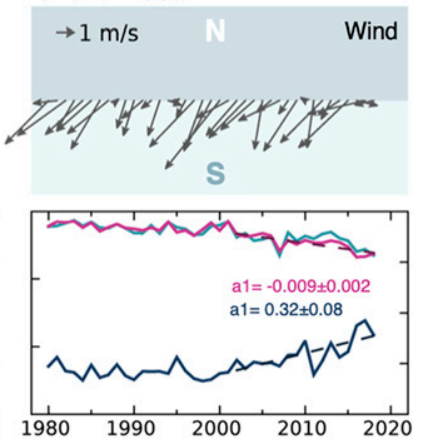

Mean melt due to ocean heat flux
Laptev Sea

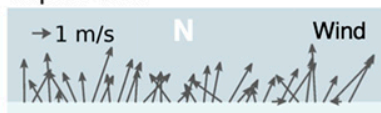

S

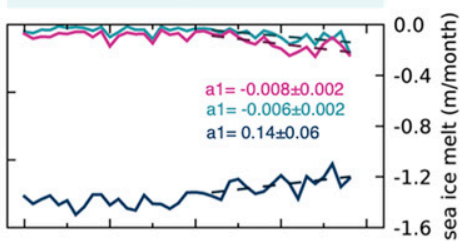

Beaufort Sea

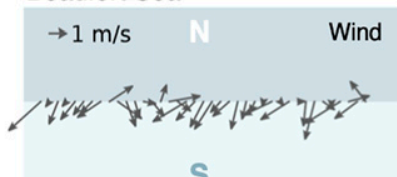

S

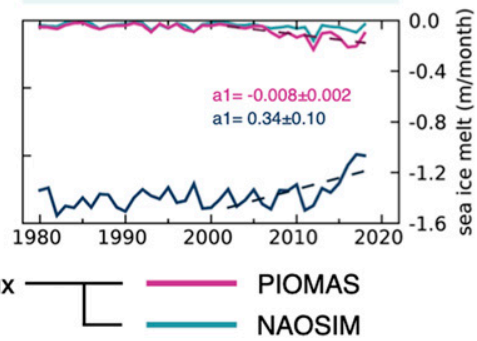

FIG. 6. Mean winter wind velocities and directions (gray panels), mean winter melt due to ocean heat flux from NAOSIM and PIOMAS, and mean winter 2-m air temperature from NCEP reanalysis data. Linear regression coefficients (2002-19) are given where trends are significant at the $95 \%$ confidence level. The regressions are highlighted as dashed lines.

find increasing surface temperatures with significant trends over 2002-19 in all regions. The strongest trend is found in the

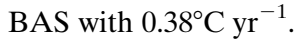

Reduced growth of sea ice through ocean heat flux has intensified over the last two decades with significant trends in BAS, KAS, and LAS. Here the impact of ocean heat flux is translated into sea ice melt, that is, reduction of sea ice and therefore valued negative. The strongest trends are found in the BAS (NAOSIM: $-0.012 \mathrm{~m} \mathrm{month}^{-1} \mathrm{yr}^{-1}$; PIOMAS: $-0.017 \mathrm{~m} \mathrm{month}^{-1} \mathrm{yr}^{-1}$ ) and KAS (NAOSIM: $-0.022 \mathrm{~m}$ month ${ }^{-1} \mathrm{yr}^{-1}$; PIOMAS: $-0.011 \mathrm{~m} \mathrm{month}^{-1} \mathrm{yr}^{-1}$ ). We note that in the BAS and KAS, PIOMAS and NAOSIM differ in magnitude, but show similar variability and trends. In fact, the differences in ocean heat flux also explain the differences in $\Delta V_{\text {thd }}$ in these regions (Fig. 3). CHS and BES reveal increasing ocean heat flux into the sea ice over the last years, but trends are only significant for PIOMAS. Translated into total volume melt, we find that simulated melt rates due to ocean heat flux, including the entire region area, are on the level of $\Delta V_{\text {thd }}$ for BAS, KAS, and CHS.

Predominant southerly wind directions are found in KAS and LAS, while CHS shows predominant northerly winds (Fig. 6). We could not find significant trends of mean zonal and meridional wind components during winters from 2002 to 2019 in any of the regions. To investigate the drivers of changes in ice growth components $\Delta V_{\mathrm{dyn}}$ and $\Delta V_{\text {thd }}$, we compute correlation coefficients between $\Delta V_{\text {dyn }}$ and $\Delta V_{\text {thd }}$, between $\Delta V_{\text {dyn }}$ and wind fields, and between $\Delta V_{\text {thd }}$ and October ice volume, surface temperature and ocean heat flux (Fig. 7). All time series have been detrended beforehand.

The terms $\Delta V_{\mathrm{dyn}}$ and $\Delta V_{\text {thd }}$ are anticorrelated; that is, increased export of sea ice correlates with an increase in $\Delta V_{\text {thd }}$ in that area (Fig. 7a). This anticorrelation is particularly strong in the LAS, considered as a main source area of sea ice. The mechanism is illustrated in sea ice growth maps in Fig. 1. When sea ice is advected away from the Siberian coast, we find negative $\Delta V_{\text {dyn }}$ and simultaneously increased $\Delta V_{\text {thd }}$ in these areas because dynamically displaced ice is replaced by new thermodynamically grown ice. Therefore, a positive trend in ice volume export (i.e., negative trend in $\Delta V_{\text {dyn }}$ in a region) will foster increasing $\Delta V_{\text {thd }}$.

Significant anticorrelation between $\Delta V_{\mathrm{dyn}}$ and southerly winds in the BAS, LAS, ESS, and CHS points to wind-driven ice import/export through the northern boundaries of the selected areas. Export through the northern boundary of the KAS seems to be driven also by ocean currents. Significant (anti)correlations with westerly winds in the ESS and BES point to wind-driven ice transport through meridional boundaries (Fig. 7b). 
a

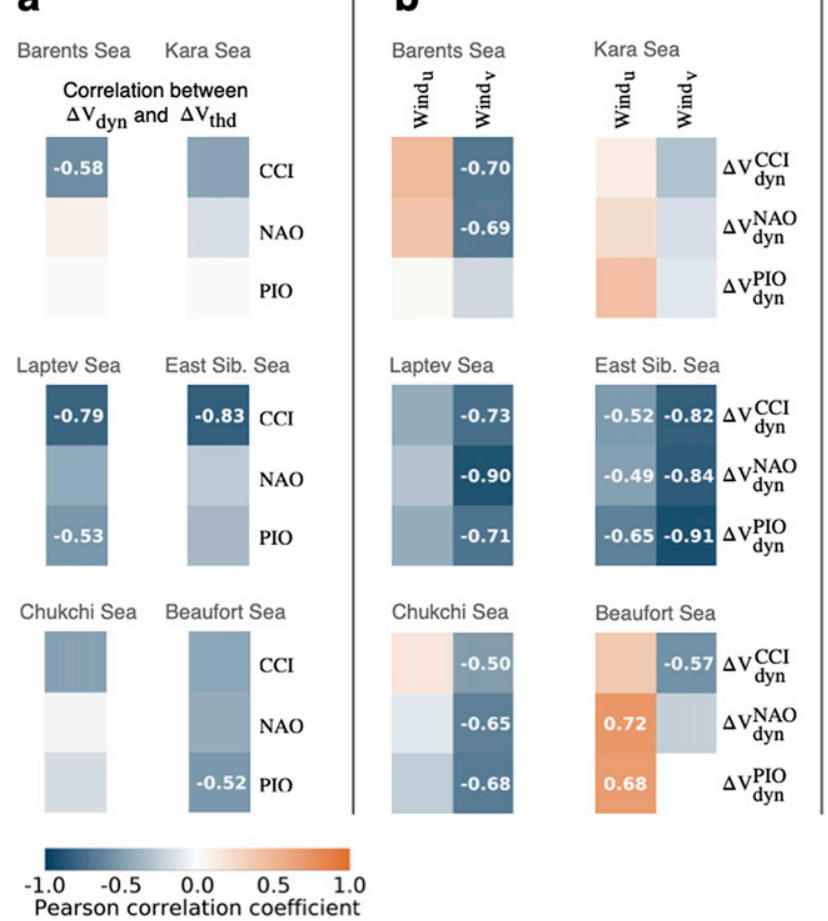

C

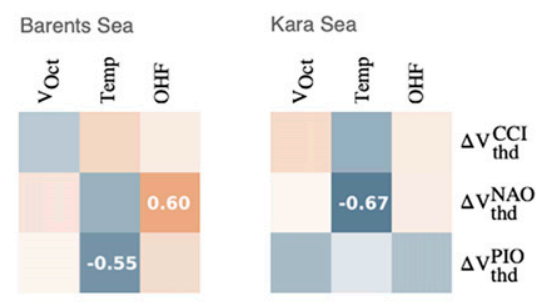

Laptev Sea

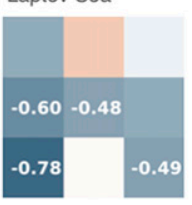

East Sib. Sea

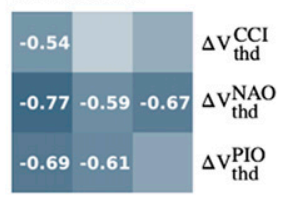

Chukchi Sea

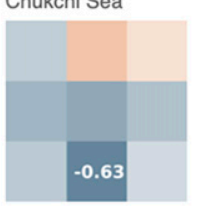

Beaufort Sea

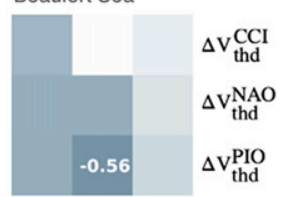

FIG. 7. (a) Pearson correlation coefficients between mean winter thermodynamic volume growth $\Delta V_{\text {thd }}$ and mean dynamic winter volume change $\Delta V_{\text {dyn }}$ for CCI CDR (CCI), NAOSIM (NAO), and PIOMAS (PIO) over 2002-19. (b) Pearson correlation coefficients between $\Delta V_{\text {dyn }}$ and northward (Wind ${ }_{v}$ ) and eastward ( Wind $_{u}$ ) wind velocities at sea level. (c) Pearson correlation coefficients between $\Delta V_{\text {thd }}$ and a set of time series including ice volume in October $V_{\text {Oct }}$, ocean heat flux (OHF) from PIOMAS, and reanalysis data of near-surface temperature (Temp). All time series have been detrended in advance. Numbers, if shown, indicate that the given correlation coefficient is significant with a $p$ value $<0.05$.

We find significant anticorrelations between the sea ice volume in October and $\Delta V_{\text {thd }}$ estimates in the ESS and LAS (Fig. 7c). Anticorrelations can be also found in the CHS and BES, but less strong. This relationship reflects the negative feedback mechanism that links lower ice volume at the beginning of the winter to increased thermodynamic ice growth. The reason why we do not see this effect in the EMS is likely due to the dominant impact of surface and ocean temperatures.

We expect enhanced anticorrelations between $\Delta V_{\text {thd }}$ and mean winter air temperatures for regions dominated by seasonal ice (BAS, KAS, LAS, and ESS), while thicker MYI, as present in the CHS and BES, grows much more slowly and therefore the effect of temperature changes on $\Delta V_{\text {thd }}$ is smaller. Indeed, we find significant anticorrelations in the BAS, KAS, LAS, and ESS (Fig. 7c), but it seems that temperaturedriven variability of $\Delta V_{\text {thd }}$ is partly compensated by the negative feedback driven by the initial ice conditions in autumn, and ocean heat flux.

Increased ocean heat flux points to warmer water masses in the upper ocean advected from the south and reducing $\Delta V_{\text {thd }}$. Simulated melt through ocean heat flux shows a positive correlation with $\Delta V_{\text {thd }}$ from satellite observations and models in the BAS, but only significant for NAOSIM (Fig. 7c). However, the increasing ocean heat flux in the BAS and KAS (Fig. 6), and at the same time decreasing $\Delta V_{\text {thd }}$ (Fig. 3), indicate the increasing role of ocean heat in Arctic winter sea ice growth.

Figure 8 highlights the different characters of the EMS and NAMS. We compare the ensemble mean of the winter $\Delta V_{\text {thd }}$ time series of PIOMAS, NAOSIM, and CCI CDR with the mean sea ice area in the previous summer (August-September) derived from satellite observations (Lavergne et al. 2019). While the EMS reveals negative trends for both summer ice area and $\Delta V_{\text {thd }}$ (Fig. 8a), the NAMS shows opposing trends (Fig. 8b). This supports our claim that the ice growth feedback in the NAMS is still active, while it is overwhelmed by the ocean heat flux in the EMS. Moreover, years with record ice extent minima, showcase the negative feedback in individual years. After trend correction we find a correlation of -0.6 in the NAMS and 0.27 in the EMS.

\section{Conclusions}

\section{a. Negative feedback versus Atlantification}

Our study confirms a negative feedback mechanism, related to new ice formation and rapid ice growth of thin ice, which stimulates replenishment of sea ice after the summer melt. However, there are regional differences, and we can pool the 
a $\quad$ EMS

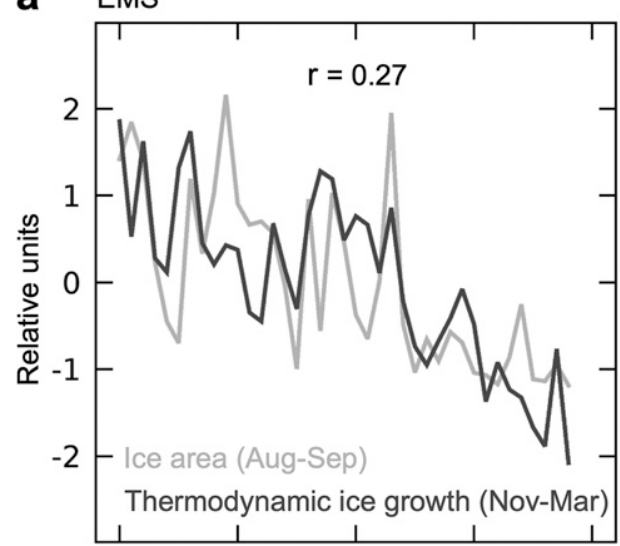

b NAMS

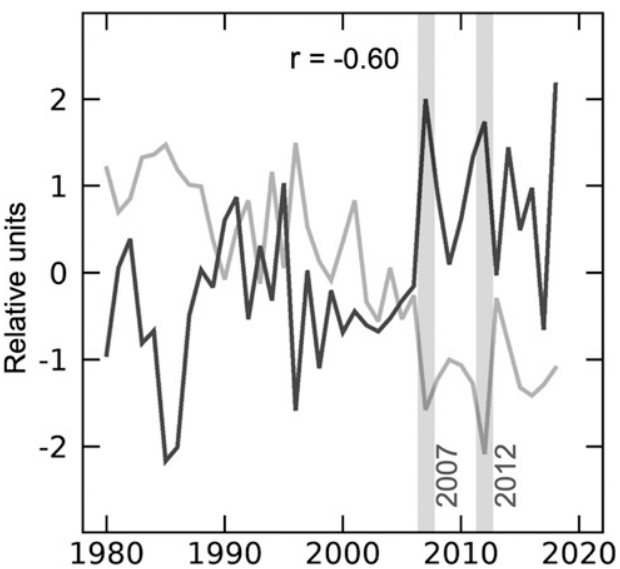

FIG. 8. Standardized mean winter thermodynamic sea ice volume growth (November-March) and sea ice area at the end of the preceding summer in (a) the European marginal seas and (b) the North America-Asia marginal seas. Gray bars highlight summer sea ice extent minima. Trend-corrected correlation coefficients $r$ are given at the top of (a) and (b).

six regions into the EMS and NAMS. The NAMS reveals a positive trend of $\Delta V_{\text {thd }}$, reflecting the negative ice growth feedback. In the EMS, despite decreasing sea ice area and thickness at the beginning of the freeze up over the last decades, and hence expected negative feedback, we find a negative trend of $\Delta V_{\text {thd }}$. Here an increase in ocean heat flux since the beginning of the millennium reduces $\Delta V_{\text {thd }}$ and overpowers the ice growth feedback consistent with advancing Atlantification (Barton et al. 2018; Polyakov et al. 2017, 2020). Increasing winter surface air temperatures and associated downwelling longwave fluxes add to a reduction in $\Delta V_{\text {thd. }}$.

Further research will have to address to which degree changes in surface air temperature in the EMS are the consequence of changes in ocean heat transport into the area or driven by the atmosphere as a result of warming and locally or remotely driven circulation changes (Ding et al. 2018; Moore et al. 2018; Hao et al. 2021). We also propose to better investigate uncertainties in the observational estimates of $\Delta V_{\text {thd }}$, such as those due to snow accumulation at the beginning of the winter season. While we do not expect qualitative changes in our findings, effects of other feedbacks (e.g., due to clouds and moisture) need to be addressed, too.

\section{b. Possible consequences for winter sea ice growth in future}

Our findings of negative trends in $\Delta V_{\text {thd }}$ in the EMS suggest that with continuing Atlantification and rising winter air temperatures, record lows in winter sea ice extent will very likely continue to occur in the upcoming years. In addition, reduced thermodynamic ice growth will also lead to thinner ice in March, which may favor early break up during summer melt, in turn aggravating the melt rates. With the advancing retreat of MYI in the ESS, CHS, and BES, these regions are increasingly dominated by FYI, which, in combination with rising upper ocean and surface air temperatures, may also lead to weakening of the negative feedback mechanism in the future. We suggest that climate models have to be analyzed with respect to the effect of the increasing Atlantification on the sea ice. If not modeled correctly in climate models, an important sensitivity in these models might be missing.

Acknowledgments. Author Ricker was supported by the ESA Climate Change Initiative (CCI) project and the Copernicus Climate Change Service (C3S). Author Zhang was supported by the NASA Cryosphere Program (NNX15AG68G and NNX17AD27G) and the National Science Foundation (PLR1603259). Author Schweiger was supported by NASA Grant 80NSSC20K1253, NSF Grant NSF-OPP-174458, and ONR Grant N00014-17-1-3162.

Data availability statement. CERSAT sea ice drift data are publicly available (ftp://ftp.ifremer.fr/ifremer/cersat/products/ gridded/psi-drift/). OSI SAF sea ice concentration data are publicly available (http://www.osi-saf.org/?q=content/sea-ice-products). The satellite sea-ice thickness data are publicly available via the CCI data portal (http://cci.esa.int/data). PIOMAS model data are available online (http://psc.apl.uw.edu/research/projects/arcticsea-ice-volume-anomaly/data/model_grid). NAOSIM model data used in this paper will be made available on the PANGAEA data archive (https://www.pangaea.de). NCEP-DOE Reanalysis 2 temperature and wind data are publicly available (https://www. psl.noaa.gov/data/gridded/data.ncep.reanalysis2.gaussian.html).

\section{REFERENCES}

Barton, B. I., Y.-D. Lenn, and C. Lique, 2018: Observed Atlantification of the Barents Sea causes the polar front to limit the expansion of winter sea ice. J. Phys. Oceanogr., 48, 1849-1866, https://doi.org/10.1175/JPO-D-18-0003.1.

Belter, H. J., T. Krumpen, S. Hendricks, J. Hoelemann, M. A. Janout, R. Ricker, and C. Haas, 2020: Satellite-based sea ice thickness changes in the Laptev Sea from 2002 to 2017: Comparison to mooring observations. Cryosphere, 14, 21892203, https://doi.org/10.5194/tc-14-2189-2020.

Bitz, C. M., and G. H. Roe, 2004: A mechanism for the high rate of sea ice thinning in the Arctic Ocean. J. Climate, 17, 3623-3632, https://doi.org/10.1175/1520-0442(2004)017<3623: AMFTHR $>2.0 . \mathrm{CO} ; 2$.

Brodzik, M. J., B. Billingsley, T. Haran, B. Raup, and M. H. Savoie, 2012: EASE-Grid 2.0: Incremental but significant improvements 
for Earth-gridded data sets. ISPRS Int. J. Geoinf., 1, 32-45, https:// doi.org/10.3390/ijgi1010032.

Castro-Morales, K., F. Kauker, M. Losch, S. Hendricks, K. RiemannCampe, and R. Gerdes, 2014: Sensitivity of simulated Arctic sea ice to realistic ice thickness distributions and snow parameterizations. J. Geophys. Res. Oceans, 119, 559-571, https://doi.org/ 10.1002/2013JC009342.

Comiso, J. C., C. L. Parkinson, R. Gersten, and L. Stock, 2008: Accelerated decline in the Arctic sea ice cover. Geophys. Res. Lett., 35, L01703, https://doi.org/10.1029/2007GL031972.

Ding, Q., and Coauthors, 2018: Fingerprints of internal drivers of Arctic sea ice loss in observations and model simulations. Nat. Geosci., 12, 28-33, https://doi.org/10.1038/s41561-018-0256-8.

Flato, G. M., and W. D. Hibler, 1991: An initial numerical investigation of the extent of sea-ice ridging. Ann. Glaciol., 15, 3136, https://doi.org/10.3189/1991AoG15-1-31-36.

Gerdes, R., M. J. Karcher, F. Kauker, and U. Schauer, 2003: Causes and development of repeated Arctic Ocean warming events. Geophys. Res. Lett., 30, 1980, https://doi.org/10.1029/2003GL018080.

Girard-Ardhuin, F., and R. Ezraty, 2012: Enhanced Arctic sea ice drift estimation merging radiometer and scatterometer data. IEEE Trans. Geosci. Remote Sens., 50, 2639-2648, https:// doi.org/10.1109/TGRS.2012.2184124.

Haas, C., A. Pfaffling, S. Hendricks, L. Rabenstein, J.-L. Etienne, and I. Rigor, 2008: Reduced ice thickness in Arctic transpolar drift favors rapid ice retreat. Geophys. Res. Lett., 35, L17501, https://doi.org/10.1029/2008GL034457.

Hao, G., J. Su, T. Vihma, and F. Huang, 2021: Trends, abrupt shifts and interannual variability of the Arctic wintertime seasonal sea ice from 1979 to 2019. Ann. Glaciol., https://doi.org/ 10.1017/aog.2020.68, in press.

Hendricks, S., S. Paul, and E. Rinne, 2018a: ESA Sea Ice Climate Change Initiative (Sea_Ice_cci): Northern Hemisphere sea ice thickness from the CryoSat-2 satellite on a monthly grid (L3C), v2.0. Centre for Environmental Data Analysis, accessed 10 January 2020, https://doi.org/10.5285/ff79d140824f42dd92b204b4f1e9e7c2.

$\ldots, \ldots$, and $\_$2018b: ESA Sea Ice Climate Change Initiative (Sea_Ice_cci): Northern Hemisphere sea ice thickness from the Envisat satellite on a monthly grid (L3C), v2.0. Centre for Environmental Data Analysis, accessed 10 January 2020, http:// doi.org/10.5285/f4c34f4f0f1d4d0da06d771f6972f180.

Hibler, W. D., 1979: A dynamic thermodynamic sea ice model. J. Phys. Oceanogr., 9, 815-846, https://doi.org/10.1175/15200485(1979)009<0815:ADTSIM>2.0.CO;2.

— , and K. Bryan, 1987: A diagnostic ice-ocean model. J. Phys. Oceanogr., 17, 987-1015, https://doi.org/10.1175/1520-0485(1987) 017<0987:ADIM>2.0.CO;2.

Kalnay, E., and Coauthors, 1996: The NCEP/NCAR 40-Year Reanalysis Project. Bull. Amer. Meteor. Soc., 77, 437-471, https://doi.org/10.1175/1520-0477(1996)077<0437:TNYRP> 2.0.CO;2.

Kanamitsu, M., W. Ebisuzaki, J. Woollen, S.-K. Yang, J. J. Hnilo, M. Fiorino, and G. L. Potter, 2002: NCEP-DOE AMIP-II Reanalysis (R-2). Bull. Amer. Meteor. Soc., 83, 1631-1644, https://doi.org/10.1175/BAMS-83-11-1631.

Kauker, F., R. Gerdes, M. Karcher, C. Köberle, and J. L. Lieser, 2003: Variability of Arctic and North Atlantic sea ice: A combined analysis of model results and observations from 1978 to 2001. J. Geophys. Res., 108, 3182, https://doi.org/ 10.1029/2002JC001573.

Keen, A., and Coauthors, 2021: An inter-comparison of the mass budget of the Arctic sea ice in CMIP6 models. Cryosphere, 15, 951-982, https://doi.org/10.5194/tc-15-951-2021.
Khvorostovsky, K., S. Hendricks, and E. Rinne, 2020: Surface properties linked to retrieval uncertainty of satellite sea-ice thickness with upward-looking sonar measurements. Remote Sens., 12, 3094, https://doi.org/10.3390/rs12183094.

King, J., and Coauthors, 2018: Comparison of freeboard retrieval and ice thickness calculation from ALS, ASIRAS, and CryoSat-2 in the Norwegian Arctic to field measurements made during the N-ICE2015 expedition. J. Geophys. Res. Oceans, 123, 1123-1141, https://doi.org/10.1002/2017JC013233.

Krumpen, T., and Coauthors, 2019: Arctic warming interrupts the transpolar drift and affects long-range transport of sea ice and ice-rafted matter. Sci. Rep., 9, 5459, https://doi.org/10.1038/ s41598-019-41456-y.

Kwok, R., 2018: Arctic sea ice thickness, volume, and multiyear ice coverage: Losses and coupled variability (1958-2018). Environ. Res. Lett., 13, 105005, https://doi.org/10.1088/1748-9326/aae3ec.

_ , and D. A. Rothrock, 2009: Decline in Arctic sea ice thickness from submarine and ICESat records: 1958-2008. Geophys. Res. Lett., 36, L15501, https://doi.org/10.1029/2009GL039035.

Labe, Z., G. Magnusdottir, and H. Stern, 2018: Variability of Arctic sea ice thickness using PIOMAS and the CESM large ensemble. J. Climate, 31, 3233-3247, https://doi.org/10.1175/ JCLI-D-17-0436.1.

Landrum, L., and M. M. Holland, 2020: Extremes become routine in an emerging new Arctic. Nat. Climate Change, 10, 11081115, https://doi.org/10.1038/s41558-020-0892-z.

Lavergne, T., and Coauthors, 2019: Version 2 of the EUMETSAT OSI SAF and ESA CCI sea-ice concentration climate data records. Cryosphere, 13, 49-78, https://doi.org/10.5194/tc-13-49-2019.

Laxon, S. W., and Coauthors, 2013: CryoSat-2 estimates of Arctic sea ice thickness and volume. Geophys. Res. Lett., 40, 732-737, https://doi.org/10.1002/grl.50193.

Lindsay, R., and A. Schweiger, 2015: Arctic sea ice thickness loss determined using subsurface, aircraft, and satellite observations. Cryosphere, 9, 269-283, https://doi.org/10.5194/tc-9-269-2015.

Meier, W., and Coauthors, 2020: 2020 sea ice outlook interim postseason report. Sea Ice Prediction Network-Phase 2, https:// www.arcus.org/sipn/sea-ice-outlook/2020/interim.

Moore, G. W. K., A. Schweiger, J. Zhang, and M. Steele, 2018: Collapse of the 2017 winter Beaufort high: A response to thinning sea ice? Geophys. Res. Lett., 45, 2860-2869, https:// doi.org/10.1002/2017GL076446.

Nandan, V., and Coauthors, 2017: Effect of snow salinity on CryoSat-2 Arctic first-year sea ice freeboard measurements. Geophys. Res. Lett., 44, 102 419-102 426, https://doi.org/10.1002/ 2017 GL074506.

Onarheim, I. H., and M. Årthun, 2017: Toward an ice-free Barents Sea. Geophys. Res. Lett., 44, 8387-8395, https://doi.org/10.1002/ 2017GL074304.

- L. H. Smedsrud, R. B. Ingvaldsen, and F. Nilsen, 2014: Loss of sea ice during winter north of Svalbard. Tellus, 66A, 23933, https://doi.org/10.3402/tellusa.v66.23933.

Owens, W. B., and P. Lemke, 1990: Sensitivity studies with a sea icemixed layer-pycnocline model in the Weddell Sea. J. Geophys. Res., 95, 9527-9538, https://doi.org/10.1029/JC095iC06p09527.

Pacanowski, R. C., 1995: MOM 2 documentation, user's guide and reference manual. GFDL Ocean Group Tech. Rep. 3, 232 pp., https://www.gfdl.gov.

Paul, S., S. Hendricks, R. Ricker, S. Kern, and E. Rinne, 2018: Empirical parametrization of Envisat freeboard retrieval of Arctic and Antarctic sea ice based on CryoSat-2: Progress in the ESA climate change initiative. Cryosphere, 12, 2437-2460, https://doi.org/10.5194/tc-12-2437-2018. 
Petty, A. A., M. M. Holland, D. A. Bailey, and N. T. Kurtz, 2018: Warm Arctic, increased winter sea ice growth? Geophys. Res. Lett., 45, 122 922-122 930, https://doi.org/10.1029/2018GL079223.

Polyakov, I. V., and Coauthors, 2017: Greater role for Atlantic inflows on sea-ice loss in the Eurasian basin of the Arctic Ocean. Science, 356, 285-291, https://doi.org/10.1126/science.aai8204.

- and Coauthors, 2020: Weakening of cold halocline layer exposes sea ice to oceanic heat in the eastern Arctic Ocean. J. Climate, 33, 8107-8123, https://doi.org/10.1175/JCLI-D-19-0976.1.

Ricker, R., S. Hendricks, V. Helm, H. Skourup, and M. Davidson, 2014: Sensitivity of CryoSat-2 Arctic sea-ice freeboard and thickness on radar-waveform interpretation. Cryosphere, $\mathbf{8}$, 1607-1622, https://doi.org/10.5194/tc-8-1607-2014.

, — - D. K. Perovich, V. Helm, and R. Gerdes, 2015: Impact of snow accumulation on CryoSat-2 range retrievals over Arctic sea ice: An observational approach with buoy data. Geophys. Res. Lett., 42, 4447-4455, https://doi.org/10.1002/ 2015 GL064081.

- — - F. Girard-Ardhuin, L. Kaleschke, C. Lique, X. TianKunze, M. Nicolaus, and T. Krumpen, 2017a: Satellite-observed drop of Arctic sea ice growth in winter 2015-2016. Geophys. Res. Lett., 44, 3236-3245, https://doi.org/10.1002/ 2016GL072244.

- — L L. Kaleschke, X. Tian-Kunze, J. King, and C. Haas, 2017b: A weekly Arctic sea-ice thickness data record from merged CryoSat-2 and SMOS satellite data. Cryosphere, 11, 1607-1623, https://doi.org/10.5194/tc-11-1607-2017.

—, F. Girard-Ardhuin, T. Krumpen, and C. Lique, 2018: Satellite-derived sea ice export and its impact on Arctic ice mass balance. Cryosphere, 12, 3017-3032, https://doi.org/ 10.5194/tc-12-3017-2018.

Saha, S., and Coauthors, 2010: The NCEP Climate Forecast System Reanalysis. Bull. Amer. Meteor. Soc., 91, 1015-1058, https:// doi.org/10.1175/2010BAMS3001.1.

— , and Coauthors, 2014: The NCEP Climate Forecast System version 2. J. Climate, 27, 2185-2208, https://doi.org/10.1175/ JCLI-D-12-00823.1.

Schweiger, A., R. Lindsay, J. Zhang, M. Steele, H. Stern, and R. Kwok, 2011: Uncertainty in modeled Arctic sea ice volume. J. Geophys. Res., 116, C00D06, https://doi.org/10.1029/ 2011JC007084.

Semtner, A. J., Jr., 1976: A model for the thermodynamic growth of sea ice in numerical investigations of climate. J. Phys. Oceanogr., 6, 379-389, https://doi.org/10.1175/1520-0485(1976)006<0379: AMFTTG $>2.0 . \mathrm{CO} ; 2$.

Smith, R. D., J. K. Dukowicz, and R. C. Malone, 1992: Parallel ocean general circulation modeling. Physica D, 60, 38-61, https://doi.org/10.1016/0167-2789(92)90225-C.

Steele, M., R. Morley, and W. Ermold, 2001: PHC: A global ocean hydrography with a high-quality Arctic Ocean. J. Climate, 14, 2079-2087, https://doi.org/10.1175/1520-0442(2001)014<2079: PAGOHW $>2.0 . \mathrm{CO} ; 2$.
Stevens, D. P., 1991: The open boundary condition in the United Kingdom Fine-Resolution Antarctic Model. J. Phys. Oceanogr., 21, 1494-1499, https://doi.org/10.1175/1520-0485(1991)021<1494: TOBCIT $>2.0 . \mathrm{CO} ; 2$

Stroeve, J., and D. Notz, 2015: Insights on past and future sea-ice evolution from combining observations and models. Global Planet. Change, 135, 119-132, https://doi.org/10.1016/j.gloplacha. 2015.10.011.

—_, A. Barrett, M. Serreze, and A. Schweiger, 2014: Using records from submarine, aircraft and satellites to evaluate climate model simulations of Arctic sea ice thickness. Cryosphere, 8, 1839-1854, https://doi.org/10.5194/tc-8-18392014.

—, D. Schroder, M. Tsamados, and D. Feltham, 2018: Warm winter, thin ice? Cryosphere, 12, 1791-1809, https://doi.org/ 10.5194/tc-12-1791-2018.

Sumata, H., T. Lavergne, F. Girard-Ardhuin, N. Kimura, M. A. Tschudi, F. Kauker, M. Karcher, and R. Gerdes, 2014: An intercomparison of Arctic ice drift products to deduce uncertainty estimates. J. Geophys. Res. Oceans, 119, 4887-4921, https://doi.org/10.1002/2013JC009724.

_, F. Kauker, M. Karcher, and R. Gerdes, 2019a: Covariance of optimal parameters of an Arctic sea ice-ocean model. Mon. Wea. Rev., 147, 2579-2602, https://doi.org/10.1175/MWR-D-18-0375.1.

,,--- , and $-2019 \mathrm{~b}$ : Simultaneous parameter optimization of an Arctic sea ice-ocean model by a genetic algorithm. Mon. Wea. Rev., 147, 1899-1926, https://doi.org/10.1175/ MWR-D-18-0360.1.

Tilling, R. L., A. Ridout, and A. Shepherd, 2018: Estimating Arctic sea ice thickness and volume using CryoSat-2 radar altimeter data. Adv. Space Res., 62, 1203-1225, https://doi.org/10.1016/ j.asr.2017.10.051.

Tschudi, M., W. Meier, J. Stewart, C. Fowler, and J. Maslanik, 2019: EASE-Grid sea ice age, version 4 [1984-2018]. NASA National Snow and Ice Data Center Distributed Active Archive Center, accessed 20 August 2020, https://doi.org/10.5067/ UTAV7490FEPB.

Wang, X., J. Key, R. Kwok, and J. Zhang, 2016: Comparison of Arctic sea ice thickness from satellites, aircraft, and PIOMAS data. Remote Sens., 8, 713, https://doi.org/10.3390/ rs8090713.

Webster, M., and Coauthors, 2018: Snow in the changing sea-ice systems. Nat. Climate Change, 8, 946-953, https://doi.org/ 10.1038/s41558-018-0286-7.

Zhang, J., and D. A. Rothrock, 2003: Modeling global sea ice with a thickness and enthalpy distribution model in generalized curvilinear coordinates. Mon. Wea. Rev., 131, 845-861, https://doi.org/ 10.1175/1520-0493(2003)131<0845:MGSIWA > 2.0.CO;2.

_, R. Lindsay, A. Schweiger, and I. Rigor, 2012: Recent changes in the dynamic properties of declining Arctic sea ice: A model study. Geophys. Res. Lett., 39, 2012GL053545, https://oi.org/ 10.1029/2012GL053545. 